Research paper

\title{
PKCdelta is a positive regulator of chondrogenesis in chicken high density micromass cell cultures
}

\author{
Csaba Matta ${ }^{\mathrm{a}, 1}$, Tamás Juhász ${ }^{\mathrm{a}, 1}$, Zsolt Szíjgyártó ${ }^{\mathrm{b}}$, Bernadett Kolozsvári ${ }^{\mathrm{b}}$, Csilla Somogyi ${ }^{\mathrm{a}}$, \\ Georgina Nagy ${ }^{\mathrm{c}}$, Pál Gergely ${ }^{\mathrm{b}}$, Róza Zákány ${ }^{\mathrm{a}, *}$ \\ ${ }^{a}$ Department of Anatomy, Histology and Embryology, Medical and Health Science Centre, University of Debrecen, Nagyerdei krt. 98, H-4032 Debrecen, Hungary

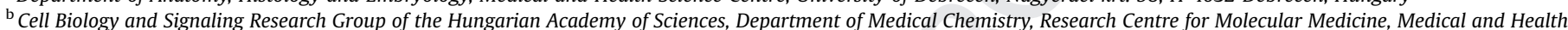 \\ Science Centre, University of Debrecen, Nagyerdei krt. 98, H-4032 Debrecen, Hungary \\ ${ }^{c}$ Department of Dermatology, Medical and Health Science Centre, University of Debrecen, Nagyerdei krt. 98, H-4032 Debrecen, Hungary
}

\section{A R T I C L E I N F O}

\section{Article history:}

Received 28 June 2010

Accepted 3 September 2010

Available online $\mathrm{xxx}$

\section{Keywords:}

Rottlerin

MEK-ERK

Sox9

shRNA

Cartilage formation

\section{Introduction}

During vertebrate limb development, at the onset of the multistep process of endochondral bone formation, undifferentiated

Abbreviations: BMP, bone morphogenic protein; BSA, bovine serum albumin; CaM-KIII, calcium/calmodulin dependent protein kinase III; CMF-PBS, calcium/ magnesium free PBS; DAG, diacyl-glycerol; DMMB, dimethyl-methylene blue; dNTP, deoxy nucleotide triphosphate; DTT, 1,4-dithio-threitol; ERK, extracellular signalregulated kinase; FGF, fibroblast growth factor; HDC, high density culture; MAPK, mitogen-activated protein kinase; MAPKAP, mitogen-activated protein kinaseactivated protein kinase; PAGE, polyacrilamide gel electrophoresis; PBS, phosphate buffered saline; PBST, phosphate buffered saline and Tween-20; PI, propidium iodide; PKB, protein kinase B; PKC, protein kinase C; PMA, phorbol-12-myristate13-acetate; PMSF, phenylmethylsulphonyl-fluoride; PRAK, p38-regulated/activated protein kinase; RT, reverse transcription; SDS, sodium-dodecyl-sulphate; TAE, TRISacetate-EDTA buffer.

* Corresponding author. Fax: +36 52255115.

E-mail address: roza@anat.med.unideb.hu (R. Zákány).

${ }^{1}$ Csaba Matta and Tamás Juhász contributed equally to the work.

0300-9084/\$ - see front matter (c) 2010 Elsevier Masson SAS. All rights reserved. doi:10.1016/j.biochi.2010.09.005 chondroprogenitor mesenchymal cells first undergo a condensation phase characterised by rapid proliferation of cells. As a result, chondrogenic mesenchymal cells become closely packed, which initiates a complex and a yet not fully understood signalling mechanism that governs differentiation of cells within these condensations into chondroblasts and then mature chondrocytes [1]. Among a number of signalling molecules, members of the phospholipid-dependent serine/threonine protein kinase C (PKC) family are known regulators of in vitro chondrogenesis $[2,3]$.

PKCs, present in almost all cell types, are involved in the regulation of various cellular processes. All known 11 PKC isoforms are divided into three subgroups based on their N-terminal regulatory domains and mechanism of activation: classical PKCs (cPKC; PKCalpha, betal, betall and gamma), novel PKCs (nPKC; PKCdelta, epsilon, eta and theta) and atypical PKCs (aPKC; PKCzeta, iota/ lambda and mu or PKD) [4]. The activation of PKCdelta also requires lipid second messengers (e.g. DAG) or tumour-promoting phorbol esters (e.g. PMA) without the requirement of $\mathrm{Ca}^{2+}$. Moreover, PKCdelta exhibits tyrosine-phosphorylation sites, which are targets 
for Src family kinases. Upon phosphorylation on tyrosine residues, PKCdelta can act as a lipid-independent enzyme [5]. One of its distinguishing characteristics is that unlike other PKC isoforms, PKCdelta activity is also involved in negative regulation of various cellular processes, e.g. suppression of proliferation and survival [6]. PKCdelta is also a crucial component of the cellular stress response, since it is required for apoptotic processes, however, some data suggest that it can also negatively influence apoptosis [7].

To identify the physiological substrates and multiple roles of various PKC isoenzymes in cellular processes, several protein kinase inhibitors have been developed with a variable specificity for individual kinases. The bisindolylmaleimide GF109203X is a general PKC inhibitor with a more potent effect on $\mathrm{CPKC}$. The indolocarbazole Gö6976 inhibits both cPKC and nPKC [8]. However, the specificity of these pharmacological inhibitors is a rather controversial issue [9]. Some protein kinase inhibitors exhibit variable degrees of specificity for different enzymes at distinct concentrations. A polyphenolic compound [5,7-dihydroxy-2,2dimethyl-6-(2,4,6-trihydroxy-3-methyl-5-acetylbenzyl)-8-cinnamoyl-1,2-chromene], rottlerin, isolated from a common Indian rain forest tree, Mallotus philippinensis, is reported to inhibit several PKC isoforms, and is thought to selectively inhibit PKCdelta 5-30-fold stronger than other PKCs at 3-6 $\mu \mathrm{M}$ concentration [4]. However, according to the findings of an in vitro enzyme activity measurement campaign conducted by the group of Davies [9], in which the specificity of various protein kinase inhibitors were assayed, rottlerin was found to inhibit many protein kinases (e.g. PRAK, MAPKAP-2) much more potently than PKCdelta, and in fact it failed to inhibit in vitro PKCdelta activity. Rottlerin was also described to inhibit some other kinases as Akt/PKB and CaM-KIII at $500 \mathrm{nM}$ [10]. Moreover, in a recent review analysing data of publications describing controversial results gained by the application of rottlerin in order to inhibit PKCdelta, it is concluded that rottlerin can be considered as a mitochondrial uncoupler rather than a direct inhibitor of this enzyme [11].

Rottlerin modulates a great variety of cellular processes in both malignant and non-malignant cells, including apoptosis in lung cancer, breast cancer, leukaemia and myeloma cells, proliferation in glioma cells, secretory activity of pancreatic acinar cells [12-14], and it is also known to regulate tumour cell migration [15]. Rottlerin has also been described to interfere with the differentiation process of various cell types of mesenchymal origin, exerting its effects at least partially by inhibiting the activity of PKCdelta [16-18]. In a recent study, Choi and his co-workers reported that rottlerin altered the migration of prechondrogenic mesenchymal cells in chicken limb bud high density cultures by modulating integrin $\beta 1$-signalling at focal adhesion complexes via a PKCdeltaindependent mechanism [10].

In this study we applied the same in vitro chondrogenesis model, in which high density cell cultures are established from chondrogenic mesenchymal cells isolated from limb buds of chicken embryos. In HDC, formation of cartilage starts with the condensation of chondroprogenitor mesenchymal cells on the first day, that after nodule formation differentiate into chondroblasts and chondrocytes predominantly on the second and third days of culturing [19]. Steps of this differentiation process are regulated by numerous growth factors and other soluble morphogens [20] and differentiating cells start to secrete cartilage-specific extracellular matrix components, such as collagen type II and aggrecan on the third day of culturing [21]. Expression of cartilage-specific matrix molecules is regulated by Sox9, a high-mobility-group domain containing transcription factor, which is started to be expressed as soon as mesenchymal cells become committed toward the chondrogenic lineage [22]. Detection of the mRNA and protein expression level and the phosphorylation status of Sox9, as well as monitoring the expression of the core protein of aggrecan and collagen type II are reliable markers of in vitro chondrogenesis.

Here we provide evidence that PKCdelta is expressed by cells of chondrifying chicken limb bud high density cultures throughout their entire differentiation process. Administration of rottlerin to cells of HDC resulted in a time and concentration dependent inhibition of metachromatic cartilage matrix production and caused a marked decrease in the phosphorylation of both Sox9 and ERK1/2, but we failed to unambiguously demonstrate inhibition of PKCdelta activity with this compound. PKCdelta gene silencing significantly lowered the activity of PKC, abolished cartilage matrix production and decreased the level of phosphorylated Sox9, but elevated the phosphorylation of ERK1/2. Our results indicate that PKCdelta acts as a positive regulator of in vitro chondrogenesis via modulation of the ERK1/2 and Sox9 pathways. Nevertheless, the chondrogenesisinhibiting effect of rottlerin is probably exerted via a PKCdeltaindependent manner, therefore we do not recommend administration of rottlerin for PKCdelta inhibition in high density cell culture systems.

\section{Materials and methods}

\subsection{Cell culturing}

Distal parts of the limb buds of Ross hybrid chicken embryos (Hamburger-Hamilton stages 22-24) were removed and primary micromass cultures of chondrifying mesenchymal cells were established from cell suspensions with a density of $1.5 \times 10^{7}$ cells/ mL. 100-100 $\mu \mathrm{L}$ droplets of the suspension were inoculated into plastic Petri dishes (Orange Scientifique, Braine-l'Alleud, Belgium). Day of inoculation is considered as day 0 . After $2 \mathrm{~h}$, colonies were nourished with Ham's F12 medium (Sigma, St. Louis, MO, USA), supplemented with $10 \%$ fetal calf serum (Gibco, Gaithersburg, MD, USA) and were kept at $37{ }^{\circ} \mathrm{C}$ in the presence of $5 \% \mathrm{CO}_{2}$ and $80 \%$ humidity in a $\mathrm{CO}_{2}$ incubator. The medium was changed on every second day.

\subsection{Transient gene silencing and pharmacologic inhibition of PKCdelta}

PKCdelta shRNA (GenScript USA Inc., Piscataway, NJ, USA) was cloned into GeneSwitch $^{\mathrm{TM}}$, the inducible protein expression system from Invitrogen (Invitrogen, Carlsbad, CA, USA). Plasmids were amplified using competent E. coli bacteria from One Shot chemical transformation kit (Invitrogen). Ampicillin or hygromycin resistant bacteria were grown on LB agar, and plasmids were isolated using MaxiPrep kit (QIAGEN, Valencia, CA, USA) according to the protocol of the manufacturer. Plasmids were delivered into cells of chondrifying cell cultures by using Lipofectamine 2000 (Invitrogen) transfection reagent. Lipofection delivery system protocol was performed on freshly isolated cell suspensions with a density of $1.5 \times 10^{7}$ cells $/ \mathrm{mL}$ by decreasing the volume of the transfection reagent by $25 \% .100$ or $30 \mu \mathrm{L}$ mixtures of the transfection reagent and cell suspension were inoculated into Petri dishes and into 24-well plates, respectively. After $2 \mathrm{~h}$ of transfection colonies were nourished with Ham's F12 medium supplemented with $10 \%$ fetal calf serum. On day 2 of culturing, $1 \mu \mathrm{M}$ mifepristone was added to the culture medium for $24 \mathrm{~h}$ for the induction of GeneSwitch ${ }^{\mathrm{TM}}$ System. Activity of PKCdelta was inhibited by applications of 2.5, 5 or $10 \mu \mathrm{M}$ rottlerin (Sigma) for $4 \mathrm{~h}$ on different days of culturing.

\subsection{Light microscopic morphology}

High-density cultures established from $30 \mu \mathrm{L}$ droplets of chondrogenic limb bud mesenchymal cells of different experimental 
groups were cultured on the surface of round coverglasses (Menzel-Gläser, Menzel GmbH, Braunschweig, Germany) placed into wells of 24-well culture plates. Cell cultures were fixed in a 4:1 mixture of absolute ethanol and 40\% formaldehyde on day 6 of culturing and were stained with $0.1 \%$ dimethyl-methylene blue (DMMB, Aldrich, Germany) dissolved in 3\% acetic acid, washed in acetic acid and were mounted in gum arabic. The amount of sulphated matrix components was determined with a semi-quantitative method, by measuring the optical density of extracted toluidine blue (Reanal, Budapest, Hungary) bound to glycosaminoglycans in mature HDC as described previously [23]. Briefly, 6 -day-old cell cultures were fixed in a solution containing $28 \%$ ethanol, $4 \%$ formalin and $2 \%$ acetic acid, stained with $0.1 \%$ toluidine blue dissolved in glycine- $\mathrm{HCl}$ buffer $(\mathrm{pH} 1.8)$ for $15 \mathrm{~min}$, and the dye bound to highly sulphated proteoglycans and glucosaminoglycans was extracted in $3 \% \mathrm{HCl}$ dissolved in absolute ethanol. Absorbance of samples containing extracted toluidine blue was measured at the wavelength of $625 \mathrm{~nm}$ on a microplate reader (Chameleon, Hidex Ltd., Turku, Finland). Optical density was measured in samples from 3 cultures of each experimental group in 3 independent experiments. Data were statistically analysed with Student's $t$-test.

\subsection{Measurement of cell proliferation with ${ }^{3} \mathrm{H}$-thymidine labelling and mitochondrial activity with MTT-assay}

$15 \mu \mathrm{L}$ droplets of cell suspension were inoculated into wells of 96-well Wallac LSC microtiter plates (PerkinElmer Life and Analytical Sciences, Shelton, CT, USA) and cells were treated similarly to those cultured in Petri dishes. Medium containing $1 \mu \mathrm{Ci} / \mathrm{mL}$ ${ }^{3} \mathrm{H}$-thymidine (185 GBq/mM ${ }^{3} \mathrm{H}$-thymidine, Amersham Biosciences, Budapest, Hungary) was added to the wells for $16 \mathrm{~h}$ on day 3 . After washing with PBS, proteins were precipitated with ice-cold 5\% trichloroacetic acid, and washed with PBS again. Colonies were airdried for 2 weeks at room temperature and radioactivity was counted by Chameleon liquid scintillation counter (Hidex). Measurements were carried out in 10 samples of each experimental group in 4 independent experiments. For investigation of cellular viability, cells cultured in wells of 96-well microtiter plates were used. $10 \mu \mathrm{L}$ MTT reagent [3-(4,5-dimethyl-thiazolyl-2)-2,5-diphenyltetrazolium bromide; $25 \mathrm{mg}$ MTT in $5 \mathrm{~mL}$ PBS] was pipetted into each well on day 3. Cells were incubated for $2 \mathrm{~h}$ at $37{ }^{\circ} \mathrm{C}$ and following addition of $100 \mu \mathrm{L}$ of MTT solubilizing solution the absorption was detected at $570 \mathrm{~nm}$ using a Chameleon microplate reader (Hidex).

\subsection{Measurement of apoptosis and necrosis by flow cytometry}

After $24 \mathrm{~h}$ of transfection or treatments with rottlerin, rate of apoptosis was measured by using AnnexinV DY 647 kit (Central European Biosystems, Budapest, Hungary). Mock-transfected cells (cultures treated only with the transfection reagent) or untreated cultures were used as control. After washing twice in CMF-PBS (calcium and magnesium free phosphate buffered saline), cells were incubated with $10 \mu \mathrm{L}$ AnnexinV DY 647 at room temperature for $10 \mathrm{~min}$. Before harvesting with $0.25 \%$ trypsin (Sigma) cells were washed with Annexin binding buffer. Necrosis was measured by using propidium-iodide (PI, Invitrogen). Cells were washed in CMF-PBS and $2 \mu \mathrm{L}$ PI was added at room temperature for $10 \mathrm{~min}$ in a dark chamber. Cell pellets were resuspended in $500 \mu \mathrm{L}$ FACS buffer (PBS supplemented with $1 \%$ BSA and $0.05 \% \mathrm{NaN}_{3}$ ) and measured on a CyFlow ${ }^{\circledR}$ space Flow Cytometer (Partec GmbH, Münster, Germany). PI was monitored at $617 \mathrm{~nm}$ and Annexin DY647 at $670 \mathrm{~nm}$. Measurement lower threshold was set on cellsize particles. Analysis was performed with WinMDI 2.8 freeware (Joseph Trotter; http://facs.scripps.edu/).

\subsection{Preparation of cell extracts}

Chondrifying cell cultures were washed with physiological $\mathrm{NaCl}$ solution and were harvested on different days of culturing. After centrifugation cell pellets were suspended in $100 \mu \mathrm{L}$ of a homogenization buffer containing $50 \mathrm{mM}$ Tris- $\mathrm{HCl}$ buffer ( $\mathrm{pH} 7.0$ ), $0.5 \mathrm{mM}$ 1,4-dithio-threitol (DTT), $10 \mu \mathrm{g} / \mathrm{mL}$ Gordox, $10 \mu \mathrm{g} / \mathrm{mL}$ leupeptin, $1 \mathrm{mM}$ phenylmethylsulphonyl-fluoride (PMSF), $5 \mathrm{mM}$ benzamidine, $10 \mu \mathrm{g} / \mathrm{mL}$ trypsin inhibitor as protease inhibitors, and $0.5 \%$ Triton X-100. Samples were snap-frozen in liquid nitrogen, then stored at $-70{ }^{\circ} \mathrm{C}$. Suspensions were sonicated by pulsing burst for three times $30 \mathrm{~s}$ by 50 cycles (Cole Palmer Ultrasonic distributor, Illinois, USA). For Western blotting and for PKCdelta activity assays, total cell lysates were used. For RT-PCR analysis, cartilage colonies were washed three times with RNase-free physiological $\mathrm{NaCl}$, then the cultures were stored at $-70{ }^{\circ} \mathrm{C}$.

\subsection{RT-PCR analysis}

Cell cultures were dissolved in Trizol (Applied BioSystems), 20\% RNase-free chloroform was added and the samples were centrifuged at $4{ }^{\circ} \mathrm{C}$ at $10,000 \times \mathrm{g}$ for $15 \mathrm{~min}$. Samples were incubated in $500 \mu \mathrm{L}$ of RNase-free 2-propanol in $-20^{\circ} \mathrm{C}$ for $1 \mathrm{~h}$, total RNA was harvested in RNase-free water and stored at $-20{ }^{\circ} \mathrm{C}$. The assay mixture for reverse transcriptase reaction contained $2 \mu \mathrm{g}$ RNA, $0.112 \mu \mathrm{M}$ oligo(dT), $0.5 \mathrm{mM}$ dNTP, 200 units M-MLV RT in $1 \times$ RT buffer. The sequences of primer pairs for polymerase chain reaction were as follows: for chicken PKCdelta (accession number: NM_001006133): 5'-CTG AGG TGA CCG TGG GTG T-3' and 5'-TTG TGG ATG GCA GCG TTA-3'; for chicken aggrecan (accession number: XM_001232949): 5'-CAA TGC AGA GTA CAG AGA-3' and 5'-TCT GTC TCA CGG ACA CCG-3'; for chicken Sox9 (accession number: AB012236): 5'-CCC CAA CGC CAT CTT CAA-3' and 5'-CTG CTG ATG CCG TAG GTA-3'; for chicken ERK1/2 (accession number: NM_204150): 5'-CAC CTC AGC AAC GAC CAC-3' and 5'-AGG AGC CCT GTA CCA ACG-3'; and for chicken GAPDH (accession number: NM_204305): 5'-GAG AAC GGG AAA CTT GTC AT $-3^{\prime}$ and $5^{\prime}-$ GGC AGG TCA GGT CAA CAA-3'. Amplifications were performed in a programmable thermocycler (PCR Express Temperature Cycling System, Hybaid, UK) as follows: $94{ }^{\circ} \mathrm{C}, 1 \mathrm{~min}$, followed by 30 cycles $\left(94{ }^{\circ} \mathrm{C}, 30 \mathrm{~s}, 54^{\circ} \mathrm{C}, 30 \mathrm{~s}, 72{ }^{\circ} \mathrm{C}, 30 \mathrm{~s}\right)$ and then $72{ }^{\circ} \mathrm{C}, 5 \mathrm{~min}$. After the addition of $1 / 5$ volume of fivefold concentrated DNA sample buffer $(0.41 \%$ bromophenol blue, $66.6 \%$ sucrose in TAE buffer containing 0.016 M EDTA, 0.19 M acetic acid and $0.4 \mathrm{M}$ Tris- $\mathrm{HCl}$; pH 8.5) PCR products were analysed by electrophoresis in $1.2 \%$ agarose gel containing ethidium bromide. Optical density of signals was measured by using Image $1.40 \mathrm{~g}$ freeware and results were normalised to the optical density of untreated control cultures.

\subsection{Western blot analysis}

Total cell lysates were examined by Western blot. Samples for SDS-PAGE were prepared by adding $1 / 5$ volume of fivefold concentrated electrophoresis sample buffer $(310 \mathrm{mM}$ Tris- $\mathrm{HCl} \mathrm{pH}$ $6.8,10 \%$ SDS, 50\% glycerol, 100 mM DTT, $0.01 \%$ bromophenol blue) to cell lysates and boiled for $10 \mathrm{~min}$. About $70-80 \mu \mathrm{g}$ of protein was separated by $10 \%$ SDS-PAGE gel for detection of PKCdelta, Sox9, p-Sox9, ERK1/2 and p-ERK1/2. Proteins were transferred electrophoretically to nitrocellulose membranes. After blocking in $5 \%$ non-fat dry milk in PBST (phosphate buffered saline with $0.1 \%$ Tween 20; $20 \mathrm{mM} \mathrm{Na}_{2} \mathrm{HPO}_{4}, 115 \mathrm{mM} \mathrm{NaCl}$; $\mathrm{pH}$ 7.4), membranes were washed and exposed to the primary antibodies overnight at $4{ }^{\circ} \mathrm{C}$. Polyclonal anti-PKCdelta antibody (Santa Cruz Inc., CA, USA) in 1:100, polyclonal anti-Sox9 antibody (Abcam, Cambridge, UK) 
in 1:600, polyclonal anti-p-Sox9 antibody (Sigma) in 1:600, polyclonal anti-ERK1/2 antibody (Sigma) in 1:1000, and polyclonal antiMAP kinase (diphosphorylated ERK1/2 on Thr and Tyr residues; Sigma) in 1:600 dilution were used. After washing three times for 10 min with PBST, membranes were incubated with the secondary antibody, anti-rabbit IgG (Bio-Rad Laboratories, CA, USA) in 1:1000 dilution in PBST containing 1\% non-fat dry milk for $2 \mathrm{~h}$ at room temperature. Signals were detected by enhanced chemiluminescence (Millipore, Billerica, MA, USA) according to the instructions of the manufacturer. Optical density of signals was measured by using Image $1.40 \mathrm{~g}$ freeware (downloaded from: http://rsb.info.nih.gov/ij/) and results were normalised to the optical density of untreated control cultures.

\subsection{Total PKC and PKCdelta enzyme activity measurements}

For PKC activity assays, cells were harvested and after centrifugation at $10,000 \times \mathrm{g}$ for $10 \mathrm{~min}$ at $4{ }^{\circ} \mathrm{C}$, supernatants were used for enzyme activity measurements. PKC activity was assayed by measuring the incorporation of ${ }^{32} \mathrm{P}$ from $\left[\gamma_{-}{ }^{32} \mathrm{P}\right]-\mathrm{ATP}$ (MP Biomedicals, Solon, OH, USA) into histone IIIS (Sigma). The reaction mixture $(40 \mu \mathrm{L})$ contained $50 \mathrm{mM}$ Tris $\mathrm{HCl}$ buffer $(\mathrm{pH} 7.5), 1 \mathrm{mg} / \mathrm{mL}$ histone IIIS, $0.8 \mathrm{mM} \mathrm{CaCl}_{2}, 0.5 \mathrm{mM}$ DTT, $1 \mu \mathrm{g} / \mathrm{mL}$ Gordox, $1 \mu \mathrm{g} / \mathrm{mL}$ leupeptin, $0.1 \mathrm{mM}$ PMSF, $0.5 \mathrm{mM}$ benzamidine, $1 \mu \mathrm{g} / \mathrm{mL}$ trypsin inhibitor as protease inhibitors, $100 \mu \mathrm{g} / \mathrm{mL}$ phosphatidylserine, $4 \mu \mathrm{g} / \mathrm{mL}$ PMA (Sigma), $0.12 \mathrm{mM}$ ATP, $6 \mathrm{mM} \mathrm{Mg}$-acetate and $\left[\gamma^{-32} \mathrm{P}\right]-$ ATP adjusted to approximately 1 million cpm/reaction mixture and appropriate amount of cell extract $(2.0-2.5 \mathrm{mg} / \mathrm{mL}$ protein). Activity measurements were performed at $30^{\circ} \mathrm{C}$. Determination of ${ }^{32} \mathrm{P}$ incorporation into histone IIIS were carried out by pipetting $30 \mu \mathrm{L}$ of the reaction mixture on filter paper squares (Whatman P81, $2 \times 2 \mathrm{~cm}$ ) after 20 min reaction time. All papers were washed three times in $0.5 \%$ phosphoric acid, dried and counted for radioactivity in a liquid scintillation counter. For measurements of PKCdelta activity, rottlerin $(10 \mu \mathrm{M})$ was administered to the reaction mixtures, and the difference caused by this compound in the total PKC activity was considered to be the contribution of PKCdelta to the overall PKC activity.

\subsection{Data processing and statistical analysis}

To determine the metachromatic cartilage matrix production, optical density of toluidine blue-stained cultures $\left(\mathrm{OD}_{625 \mathrm{~nm}}\right)$ was measured in samples from 3 cultures of each experimental group in 3 independent experiments. For the detection of cellular proliferation rate $\left({ }^{3} \mathrm{H}\right.$-thymidine incorporation assay) or mitochondrial activity (MTT assay), measurements were carried out in 10 samples of each experimental group in 4 independent experiments. Data are mean values \pm standard error of the mean and were statistically analysed with Student's $t$-test $(P<0.01)$. Data analysis of FACS measurement results was performed with WinMDI 2.8 freeware (Joseph Trotter; http://facs.scripps.edu/). For RT-PCR reactions and Western blot analyses, optical density of signals was measured by using Image $1.40 \mathrm{~g}$ freeware and results were normalised to the optical density of untreated control cultures. Data of PKC enzyme activity measurements were statistically analysed with Student's $t$-test $(P<0.01)$.

\section{Results}

\subsection{PKCdelta expression and activity in cells of HDC}

To identify the mRNA and protein expression pattern of PKCdelta during in vitro chondrogenic differentiation of chicken mesenchymal cells, RT-PCR reactions and Western blot analyses were performed, respectively. The mRNA sequence of chicken PKCdelta was downloaded from GenBank and a specific primer pair was designed for amplification.

mRNA expression of chicken PKCdelta in cells of HDC followed an unchanged pattern during differentiation from day 0 , with only slightly higher expression levels on days 1 and 2 (Fig. 1A). The protein expression profile of chicken PKCdelta, however, followed a peak-like pattern and showed an almost four-fold elevation by days 2 and 3 compared to day 0 , as revealed by Western blot analyses (Fig. 1B). Under control conditions, the enzyme activity of PKCdelta in cells of HCD exhibited a pattern that is closely correlated with the protein expression, i.e. the enzyme activity was higher on days 1-4 compared to day 0 . Activity of PKCdelta then decreased toward the end of the culturing period (Fig. 1C).

\section{A RT-PCR}
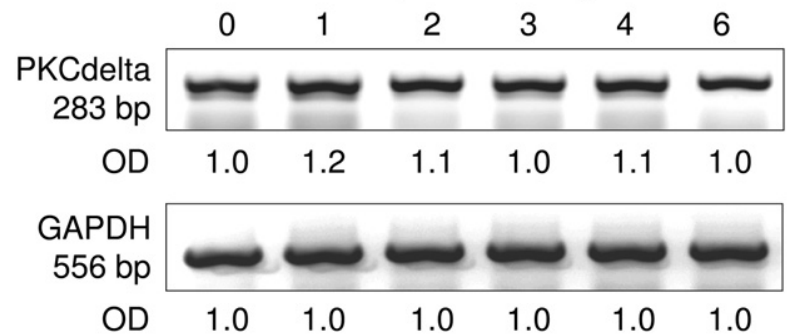

B Western blot

\section{Days of culturing}

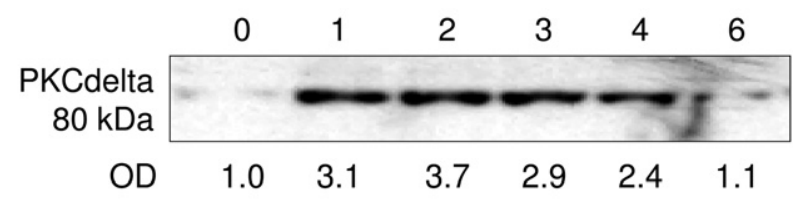

\section{PKC enzyme activity}

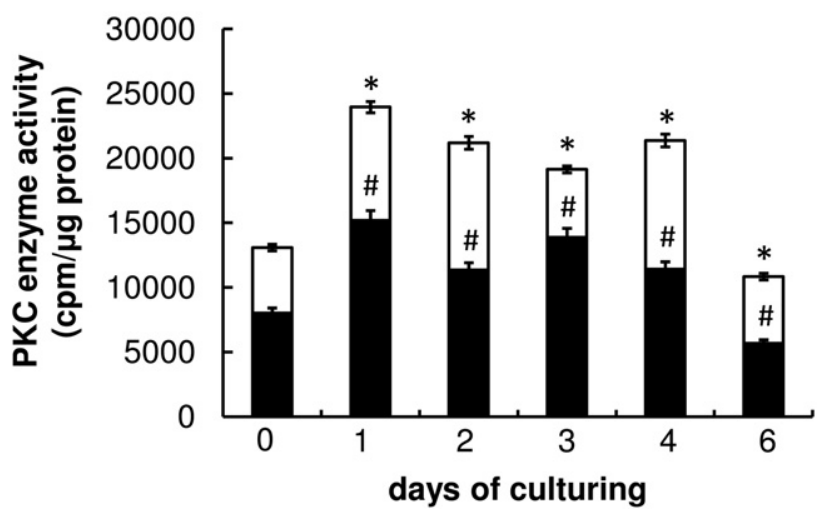

Fig. 1. mRNA (A) and protein (B) expression of PKCdelta in cells of chondrifying micromass cultures on various days of culturing. For RT-PCR reactions, GAPDH was used as a control. Optical density of signals was measured and results were normalised to the optical density of 0-day-old cultures. Representative data of 3 independent experiments. Total PKC and PKCdelta enzyme activity (C) in cells of HDC on various days of culturing. The white upper part of each bar represents the contribution of PKCdelta enzyme activity (i.e. difference caused by rottlerin in cell-free extracts) to total PKC enzyme activity, whereas the black lower parts represent the activity of other PKC isoforms. Significant changes are indicated by * and ${ }^{\#}(P<0.01)$ as an increase or decrease in total PKC $\left(^{\#}\right)$ and PKCdelta $\left(^{*}\right)$ enzyme activity as compared to the respective control (day 0 ). Representative data of 3 independent experiments. 


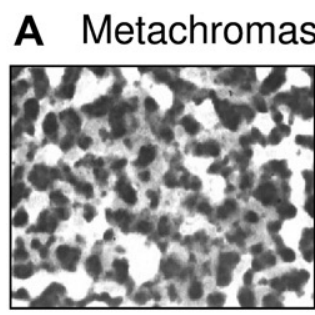

Control

$\left(\mathrm{OD}_{625}=100 \%\right)$

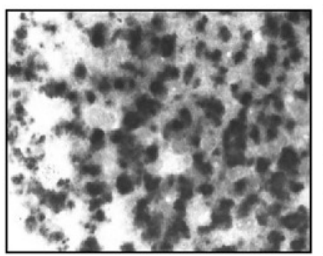

$+2.5 \mu \mathrm{M}$ rottlerin

day $1,1 \times 4 \mathrm{~h}$

$\left(\mathrm{OD}_{625}=89 \%\right)$

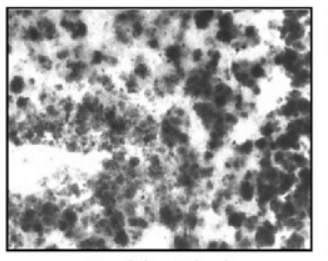

$+5 \mu \mathrm{M}$ rottlerin

day $1,1 \times 4 \mathrm{~h}$

$\left(\mathrm{OD}_{625}=87 \%\right)$

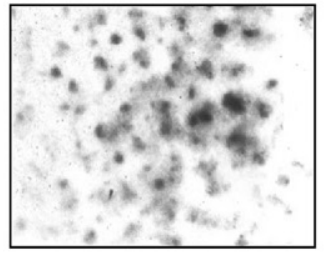

$+2.5 \mu \mathrm{M}$ rottlerin days 2 and $3,2 \times 4 \mathrm{~h}$ $\left(\mathrm{OD}_{625}=24 \%^{*}\right)$

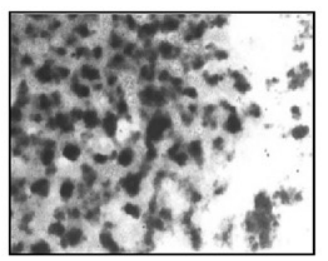

$+2.5 \mu \mathrm{M}$ rottlerin

day $2,1 \times 4 \mathrm{~h}$

$\left(\mathrm{OD}_{625}=58 \%^{*}\right)$

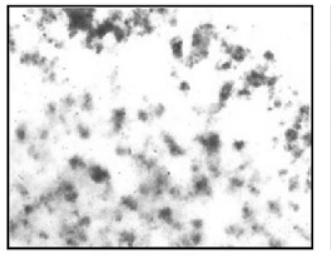

$+5 \mu \mathrm{M}$ rottlerin day $2,1 \times 4 \mathrm{~h}$

$\left(\mathrm{OD}_{625}=50 \%{ }^{*}\right)$

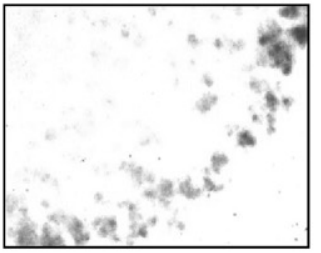

$+5 \mu \mathrm{M}$ rottlerin

days 2 and $3,2 \times 4 h$

$\left(\mathrm{OD}_{625}=12 \%{ }^{*}\right)$

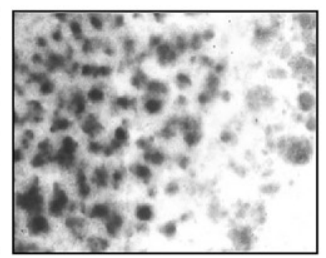

$+2.5 \mu \mathrm{M}$ rottlerin

day $3,1 \times 4 \mathrm{~h}$

$\left(\mathrm{OD}_{625}=52 \%{ }^{*}\right)$

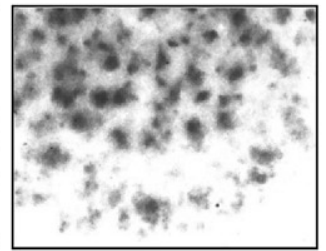

$+5 \mu \mathrm{M}$ rottlerin

day $3,1 \times 4 \mathrm{~h}$

$\left(\mathrm{OD}_{625}=40 \%{ }^{*}\right)$

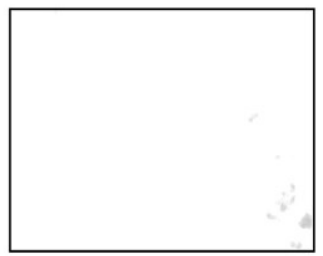

$+10 \mu \mathrm{M}$ rottlerin

days 2 and $3,2 \times 4 \mathrm{~h}$

$\left(\mathrm{OD}_{625}=1 \%{ }^{*}\right)$

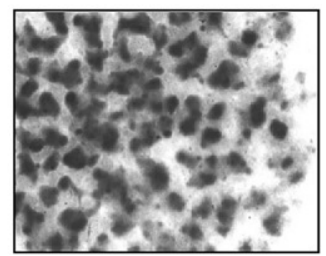

$+2.5 \mu \mathrm{M}$ rottlerin

day $4,1 \times 4 \mathrm{~h}$

$\left(\mathrm{OD}_{625}=35 \%{ }^{*}\right)$

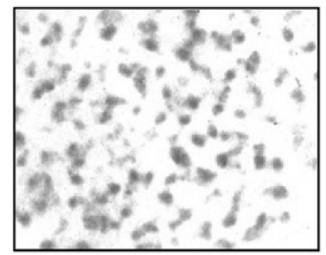

$+5 \mu \mathrm{M}$ rottlerin

day $4,1 \times 4 \mathrm{~h}$

$\left(\mathrm{OD}_{625}=11 \%^{*}\right)$

B MTT-assay and ${ }^{3} \mathrm{H}$-thymidine incorporation

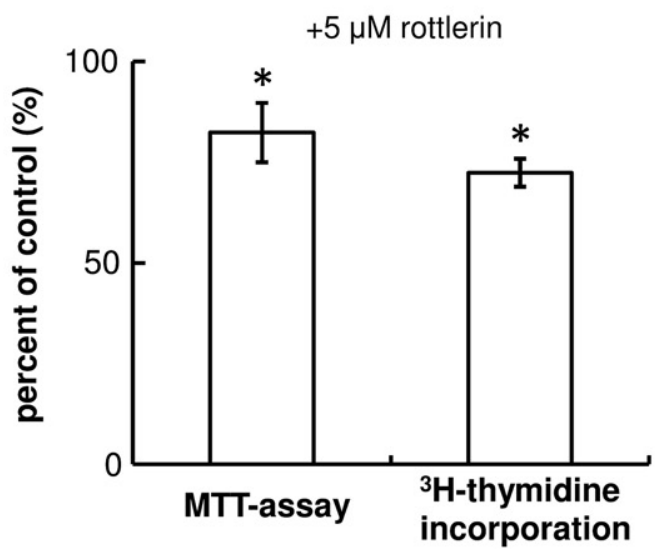

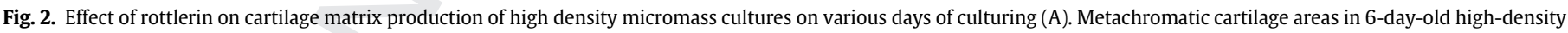

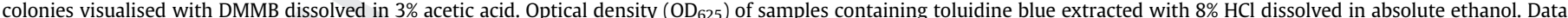

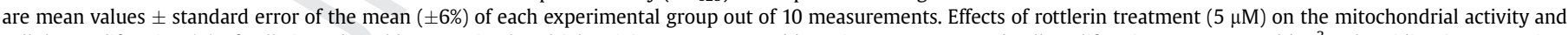

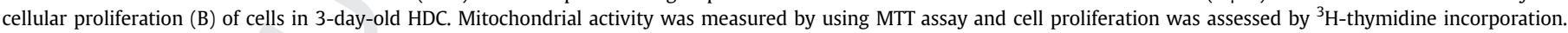

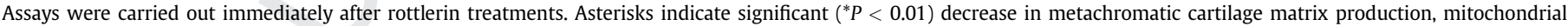
activity or cellular proliferation rate as compared to the respective control (day 3). Representative data of 3 independent experiments.

\subsection{Rottlerin inhibits in vitro chondrogenesis in a time and concentration-dependent manner}

To identify the effects of rottlerin on cartilage differentiation in vitro, rottlerin at concentrations of 2.5 and $5 \mu \mathrm{M}$ was administered to cells of HDC on various days of culturing. Cartilage matrix production was analysed by metachromatic staining procedures with dimethyl-methylene blue and toluidine blue on day 6 of culturing. As seen in Figs. 2A and $5 \mu \mathrm{M}$ rottlerin inhibited in vitro chondrogenesis in a time- and concentration-dependent manner with the strongest inhibition on days 2 and 3 (12\% of untreated control cultures). When rottlerin was administered in $10 \mu \mathrm{M}$ or higher concentrations on either day of culturing, cartilage matrix production was completely blocked as demonstrated by the complete loss of metachromatic staining. Because treatments by either 2.5 or $5 \mu \mathrm{M}$ rottlerin resulted in similar qualitative results, in 
A RT-PCR

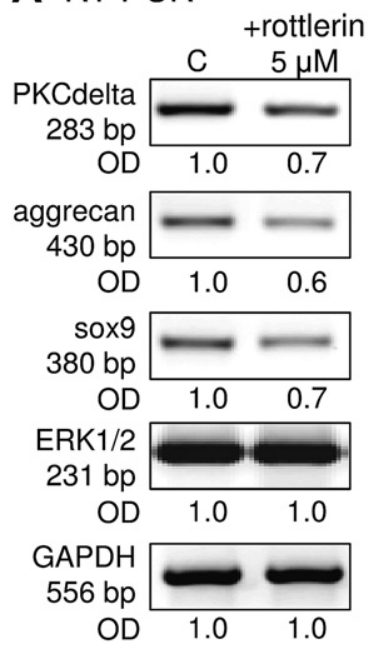

B Western blot

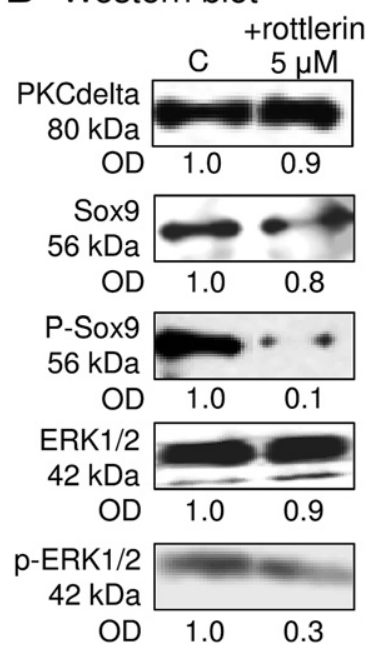

Fig. 3. Effect of $5 \mu \mathrm{M}$ rottlerin treatment on the mRNA expression of PKCdelta, aggrecan, Sox9 transcription factor and ERK1/2 (A); the protein expression of PKCdelta and ERK1/2; the protein expression and phosphorylation of Sox9 (B) in HDC on day 3 of culturing. For RT-PCR reactions GAPDH was used as a control. Optical density of signals was measured and results were normalised to the optical density of respective control cultures. Representative data of 3 independent experiments.

the following set of experiments we only used the concentration of $5 \mu \mathrm{M}$.

Since the observed decrease in metachromatic staining could have been caused by cytotoxic and/or anti-proliferative effects of rottlerin, mitochondrial activity and cellular proliferation assays were performed, respectively. Rottlerin administered on days 2 and 3 for $4 \mathrm{~h}$ in $5 \mu \mathrm{M}$ concentration caused a slight, but significant decrease in metabolic activity in cells of HDC and it also caused a significant decrease in proliferation rate as revealed by MTT and radioactively labelled thymidine incorporation assays, respectively (Fig. 2B). Rottlerin treatments did not result in the elevation of apoptotic or necrotic rate in cells of HDC in either concentration according to FACS analyses (data are shown in the Supporting information).

To evaluate the role of rottlerin in the molecular regulation of in vitro chondrogenesis, mRNA and protein levels of PKCdelta, aggrecan core protein and Sox9, the major cartilage-specific transcription factor, were detected by RT-PCR and Western blot reactions, respectively. Exposure to rottlerin resulted in a marked decrease in the mRNA expression of PKCdelta (Fig. 3A), however, only a slight reduction was observed in its protein expression level when rottlerin was applied at a concentration of $5 \mu \mathrm{M}$ (Fig. 3B). A significant decrease in the mRNA levels of both aggrecan core protein and Sox9 was detected under the effect of rottlerin treatments (Fig. 3A). Western blot analyses showed that exposure to $5 \mu \mathrm{M}$ rottlerin only slightly reduced the protein level of Sox9, whereas a significant decrease was observed in its phosphorylation level after the administration of the inhibitor (Fig. 3B). These findings demonstrate that rottlerin decreases cartilage formation, at least partly, via inhibition of cartilage differentiation.

Since MAP-kinases, particularly ERK $1 / 2$ is one of the key regulators that influence in vitro chondrogenesis, we examined whether the observed decrease in cartilage matrix production was regulated by an ERK1/2 dependent pathway. Although administration of rottlerin did not alter the mRNA expression level of ERK1/2 and protein expression was also only slightly modified, exposure to $5 \mu \mathrm{M}$ rottlerin significantly reduced the level of phosphorylated ERK1/2 (Fig. 3A-B). Furthermore, administration of $5 \mu \mathrm{M}$ rottlerin to cells on days 2 and 3 caused alterations in the activity of PKCdelta measured on day 3 of culturing in cell-free extracts of HDC, but the direction of these changes was completely inconsistent (data not shown). These findings suggest that the aforementioned effects of rottlerin on cartilage differentiation could have mostly been caused by its aspecific, non-PKCdelta-dependent effects.

\subsection{Inhibition of PKCdelta by shRNA transfection inhibits in vitro chondrogenesis}

Although rottlerin is widely known as a selective inhibitor of PKCdelta, some data are available on its PKCdelta-independent effects [24] and our results also suggested such a possibility. Therefore, we selectively inhibited PKCdelta expression using specifically designed shRNA to clarify the role of PKCdelta in chondrogenesis. The PKCdelta shRNA sequence was cloned into GeneSwitch, the inducible protein expression system from Invitrogen, and transfected into primary chondroprogenitor mesenchymal cells on day 0 , prior to their attachment by using Lipofectamine 2000 transfection reagent. On day 2 of culturing, $1 \mu \mathrm{M}$ mifepristone was added to the culture medium for $24 \mathrm{~h}$ for the induction of GeneSwitch System. Mifepristone at the applied concentration did not alter the amount of in vitro cartilage matrix production by culturing day 6 (data are shown in the Supporting information).

Introduction of empty GeneSwitch vector alone into cells of HDC resulted in a significant decrease of metachromatic cartilage matrix production ( $40 \%$ of mock-transfected control cultures) as revealed by dimethyl-methylene blue and toluidine blue staining procedures on day 6 of culturing (Fig. 4A). Introduction of PKCdelta shRNA-containing GeneSwitch resulted in an even stronger inhibition (5\% of mock-transfected control cultures), and the complete loss of the metachromatic cartilage matrix (Fig. 4A).

In spite of the pronounced inhibition of cartilage matrix production, mitochondrial activity of cells transfected with either empty or PKCdelta shRNA-containing GeneSwitch constructs remained unchanged compared to mock-transfected control cells as revealed by MTT assays, and the rate of cellular proliferation also did not show any alterations in either case (Fig. 4B). Cellular viability and apoptosis assays performed by measuring the ratio of propidium iodide and Annexin V DY647 stained cells using FACS analysis revealed that transfection with the empty vector did not cause any change in these parameters, whereas introduction of the PKCdelta shRNA vector resulted in a very slight elevation of apoptotic (2\%) and necrotic (1\%) cell death (Fig. 4C). These findings demonstrate that the observed decrease in cartilage matrix production was not caused by altered cellular viability, mitochondrial activity, proliferation or apoptotic rate.

We also wanted to examine the signalling mechanism underlying the aforementioned alterations of in vitro cartilage matrix production. To evaluate the efficiency of gene silencing, RT-PCR and Western blot analyses were performed. Although mRNA expression of PKCdelta decreased only to a lesser extent as a result of shRNA expression (Fig. 5A), however, at the protein level it exhibited a marked inhibition (30\% of cultures transfected with the empty vector) reflecting on the efficiency of PKCdelta gene silencing (Fig. 5B). While PKCdelta gene silencing did not change the mRNA expression of Sox9, and the mRNA level of aggrecan core protein only exhibited slight alterations, the protein level of Sox9 showed a marked decrease as a result of introduction of PKCdelta shRNA, as revealed by RT-PCR and Western blot analyses, respectively (Fig. 5A-B). Although PKCdelta gene silencing did not affect either the mRNA or the protein expression of ERK1/2, a significant (twofold) increase in its phosphorylated form was observed, implicating the involvement of this pathway in the signal transduction 


\section{A Metachromasia}

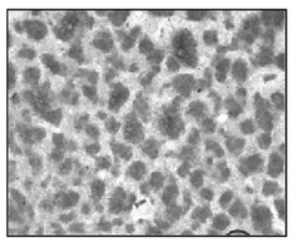

Mock-transfected,

Lipofectamine 2000

$\left(\mathrm{OD}_{625}=100 \%\right)$
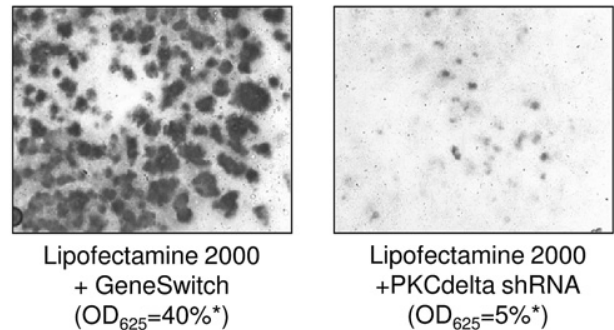

\section{B MTT-assay and ${ }^{3} \mathrm{H}$-thymidine incorporation}

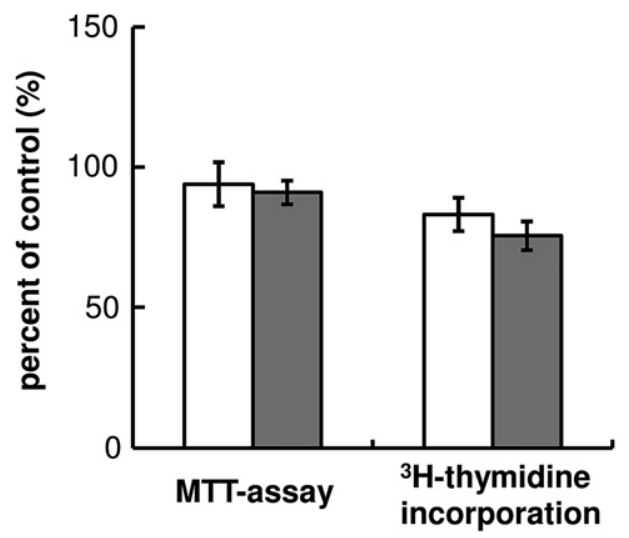

\section{Apoptosis and cellular viability assay}
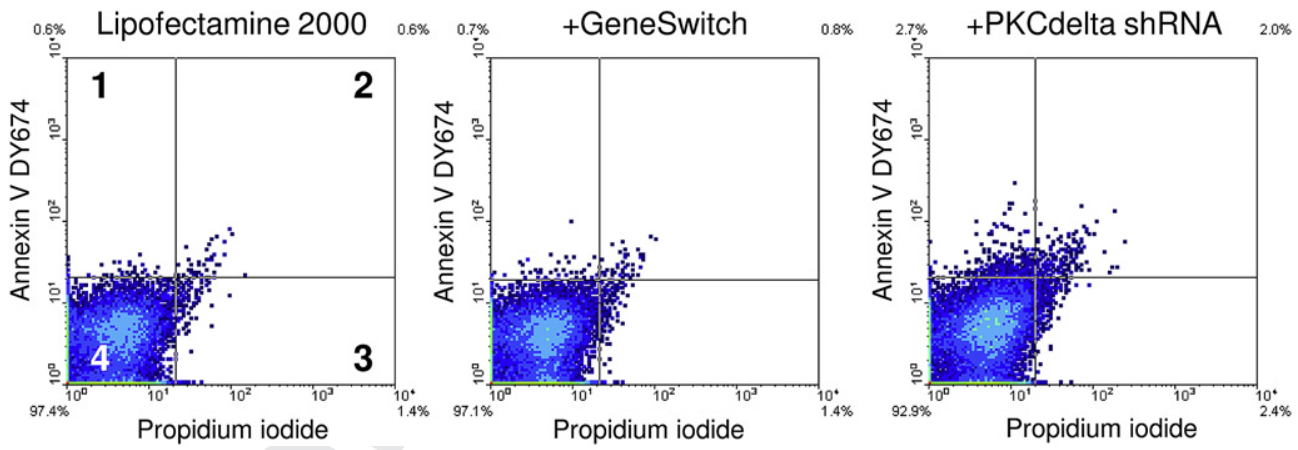

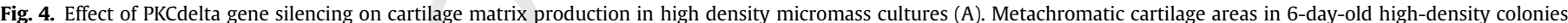

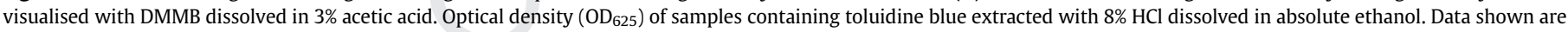

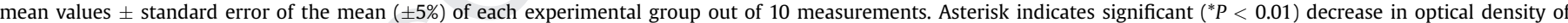

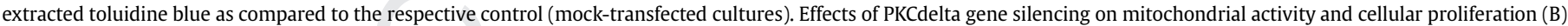

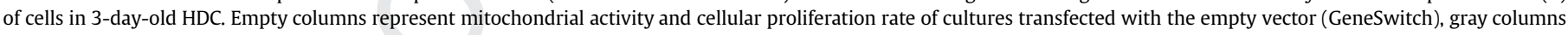

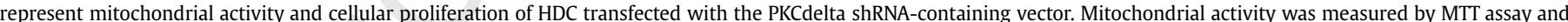

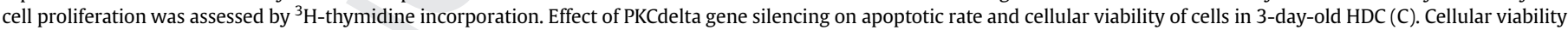

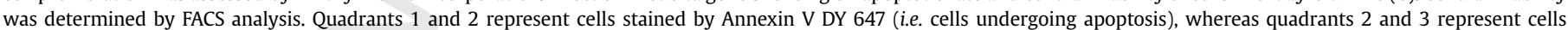

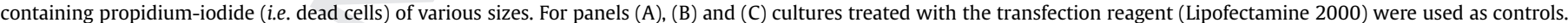

mechanism of PKCdelta in cells of chondrifying micromass cultures. Administration of either the empty or the PKCdelta shRNA-containing vector resulted in a significant decrease in PKC activity of cells in HDC, with a more than $50 \%$ reduction in cultures transfected with PKCdelta shRNA (Fig. 5C) as compared to mock-transfected cultures.

\subsection{Protein expression and phosphorylation status profiles of Sox9 and ERK1/2 exhibit a time-dependent pattern in differentiating HDC}

Since both the cartilage-specific transcription factor Sox9 and the dual-specificity MAPK ERK1/2 are key regulators of in vitro chondrogenesis, and their activity can be modified by reversible phosphorylation, we examined their protein expression as well as the phosphorylation status pattern in untreated control cultures during the 6-day-long culturing period. As shown in Fig. 6, the protein expression profiles of ERK1/2 and its dual phosphorylated (fully active) form demonstrate that the activity of ERK $1 / 2$ is the highest in young chondroblasts (i.e. in cells of 3-day-old HDC) and becomes lower in differentiated chondrocytes (6-day-old HDC). Although Sox9 is readily expressed in chondroprogenitor mesenchymal cells (0-day-old HDC), we detected a 5-fold elevation in 2-day-old cultures, when the cells start their differentiation programme. In differentiated cultures, Sox9 expression shows 


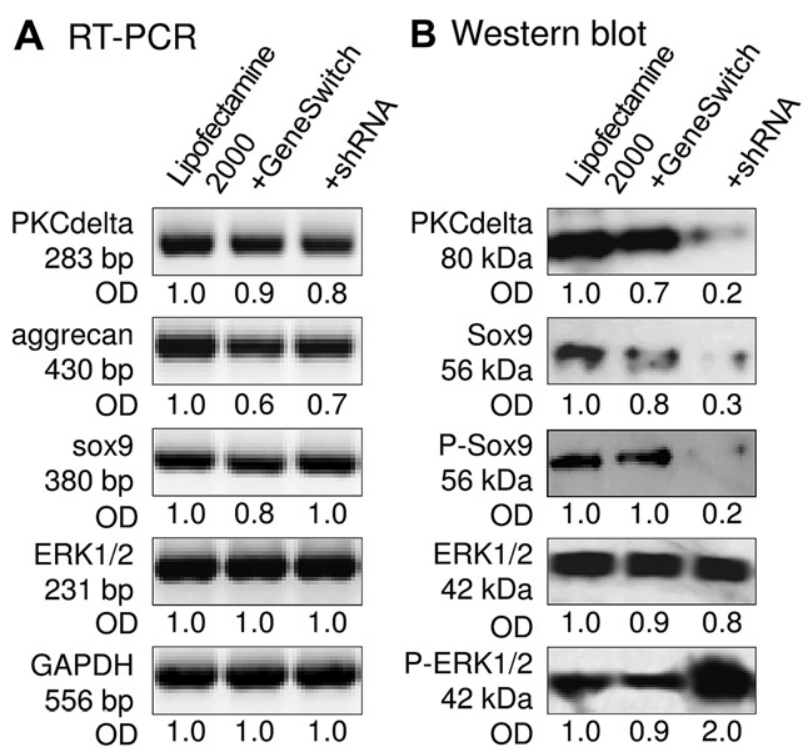

\section{PKC enzyme activity}

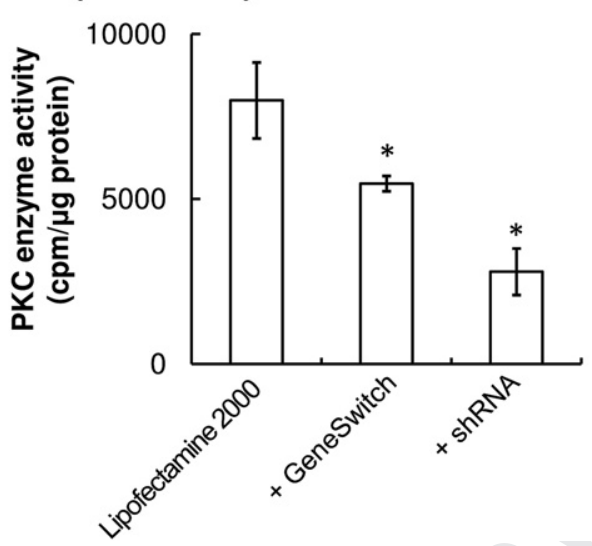

Fig. 5. Effect of PKCdelta gene silencing on the mRNA expression of PKCdelta, aggrecan and Sox9 transcription factor (A); protein expression of PKCdelta; protein expression and phosphorylation of Sox9 and ERK1/2 (B) in 3-day-old HDC. For RT-PCR reactions, GAPDH was used as a control. Optical density of signals was measured and results were normalised to the optical density of respective control cultures. Representative data of three independent experiments. PKC activity (C) in cells of HDC after PKCdelta gene silencing on day 3 of culturing. Asterisk indicates significant $\left({ }^{*} P<0.01\right)$ decrease in enzyme activity as compared to the mock-transfected control (day 3). Representative data of 3 independent experiments. For panels (A), (B) and (C) cultures treated with the transfection reagent (Lipofectamine 2000) were used as controls.

a decrease, but it does not reach the baseline level again. Changes in the phosphorylation level of Sox 9 are not significant, nonetheless, it exhibits a similar pattern (Fig. 6).

\section{Discussion}

It has long been known that various PKC isoenzymes are involved in the chondrogenic differentiation of chicken limb micromass cultures. PKC enzyme activity proved to be detectable in cells of HDC with characteristic changes during differentiation, and conversely, exposure of cultures to long-term phorbol-12-myristate-13-acetate (PMA) treatments blocked the differentiation process and abolished in vitro cartilage matrix production [25]. In a study conducted by Choi and his colleagues the expression profiles of classic (PKCalpha and gamma), novel (PKCepsilon) and atypical (PKCzeta, lambda and iota) protein kinase $C$ isoenzymes have been described during the differentiation of chicken

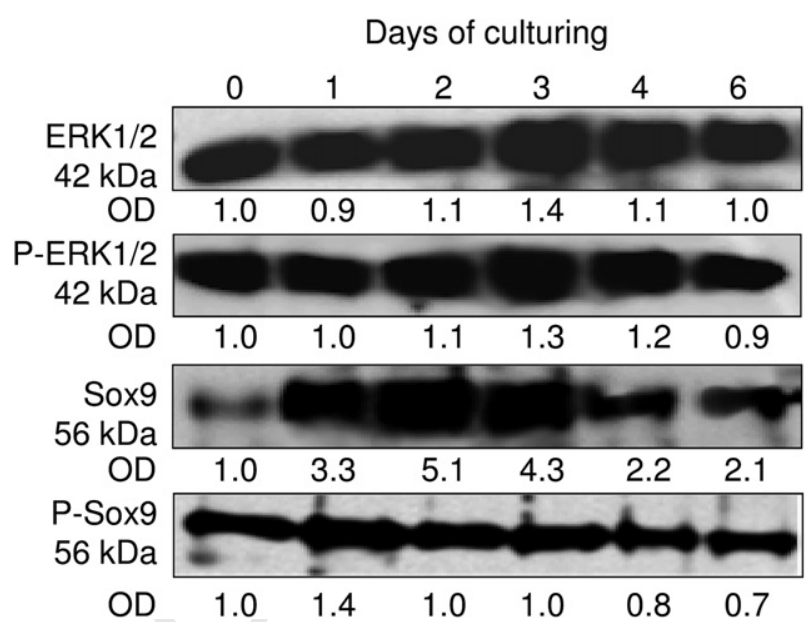

Fig. 6. Protein expression profile and phosphorylation status of Sox9 transcription factor and ERK1/2 in HDC during the 6-day-long culturing period. Optical density of signals was measured and results were normalised to the optical density of 0-day-old cultures. Representative data of 3 independent experiments.

micromass cultures and they showed that expression of various cPKC and nPKC isoforms is mostly required at the early stages of in vitro cartilage formation [3]. However, Choi and his group failed to detect PKCdelta expression in cells of HDC with the antibodies employed [3]. It has also been reported that protein kinase A signalling regulates in vitro chondrogenesis of chicken mesenchymal cells via the PKCalpha pathway [26]. PKCdelta expression in cells of HDC was reported for the first time by Grill and his colleagues, who confirmed its protein expression by immunochemical and immunocytochemical approaches [27]. Recently, Choi and his colleagues demonstrated the protein expression of PKCdelta by Western blot analyses in cells of HDC [10], when they investigated the involvement of this signal molecule in the regulation of the formation of prechondrogenic nodules. Consistent with their data, our results also showed a marked increase in PKCdelta protein expression at the beginning of the 6-day-long culturing period, followed by a decrease in its expression level. We also confirmed these findings by PKCdelta enzyme activity assays, with the maximum levels of activity corresponding to the highest levels of protein expression on culturing days 1-4. Correspondence of these patterns to the onset of chondrogenic differentiation of cells in HDC supports our idea that PKCdelta is a good candidate among PKC isoforms to be involved in the regulation of signalling mechanisms leading to in vitro cartilage formation.

In the subsequent set of experiments rottlerin (mallotoxin), described as an inhibitor of PKCdelta activity in some publications [28-30], was administered to cells of HDC. Rottlerin treatments resulted in a decrease of cartilage matrix production in a concentration and time dependent manner, including days 1 or 2 of culturing, when condensation and nodule formation of chondrogenic mesenchymal cells take place. These results are in agreement with the findings of Choi and his colleagues, who reported that rottlerin, via modulation of Akt-signalling and integrin $\beta 1$-mediated pathways, might be negatively involved in the regulation of the migratory potential of chondroprogenitor cells in chicken limb bud-derived HDC, but in a PKCdelta-independent manner [10].

Since the decrease in metachromatic cartilage matrix production we observed might have resulted from the reduced cellular viability and/or decreased cellular proliferation rate, mitochondrial oxidase activity (MTT) and proliferation (radioactively labelled thymidine incorporation) assays were performed. While the cellular viability was only lowered to a lesser, but still significant extent, a more pronounced decrease in the rate of proliferation was 
observed. The latter result is consistent with the anti-proliferative effect of rottlerin on HaCaT keratinocytes [24]. Administration of rottlerin did not induce either apoptosis or necrosis in cells of HDC. As rottlerin is described as a mitochondrial uncoupler of different mammalian cell types rather than a direct PKCdelta inhibitor in some recent publications [11,31], these findings may reflect on a difference in mitochondrial sensitivity to rottlerin of chicken compared to mammalian cells. mRNA and protein expression of Sox9, the key chondrogenic transcription factor decreased after rottlerin treatments, moreover, phosphorylation of Sox9 (resulting in a more active form of this transcription factor) was almost completely abolished. The observed decrease in the phosphorylated form of Sox9 protein could be, at least partially, accounted for the reduced cartilage matrix production after the administration of rottlerin.

The ERK pathway, also known as the MEK-ERK kinase cascade, is one of the key cytoplasmic signal transduction pathways governing proliferation, survival and differentiation of eukaryotic cells. The role of this crucial signal pathway in the regulation of chondrogenesis is rather controversial and probably depends either on the experimental model or/and the methods applied. ERK1/2 was reported as a negative regulator of chondrogenesis in both HDC [32,33] and C3H10T mouse embryonic mesenchymal cells [34]. In these experiments the function of ERK $1 / 2$ was assessed by the application of pharmacological inhibitors PD098059 or U0126 [35]. On the contrary, it seemed to promote chondrogenesis in adult human bone marrow derived multipotent progenitor cells when the gene silencing technique was the approach [36]. Nonetheless, we found that the protein expression profiles of ERK1/2 and its dual phosphorylated (fully active) form show that the activity of ERK1/2 is the highest in young chondroblasts (i.e. in cells of 3-day-old HDC) and becomes lower in differentiated chondrocytes (i.e. 6-day-old HDC) (Fig. 6). In our current experiments neither the mRNA, nor the protein expression of ERK1/2 was altered after treatments with rottlerin, but its phosphorylated form was almost completely diminished. Our results correspond with that of another study conducted by Tapia and his colleagues on pancreatic acinar cells, where rottlerin also proved to inhibit MAPK-activation [14].

Since rottlerin has been described as a factor having both PKCdelta dependent and independent effects often leading to contradictory results on various tissue and cell types [14,24], we were prompted to apply targeted PKCdelta mRNA silencing to clarify the role of PKCdelta activity during the differentiation of chondrogenic mesenchymal cells. Transfection with PKCdelta shRNA and subsequent transient gene silencing of cellular PKCdelta almost completely blocked in vitro chondrogenesis. Neither mitochondrial activity, nor cellular proliferation rate were significantly affected by the introduction of either the empty or the PKCdelta shRNA-containing vectors into cells of HDC, furthermore, PKCdelta gene silencing did not induce significant apoptotic and/or necrotic cell death rate of chondrogenic cells. In contrast to our results, PKCdelta has been reported as an accelerator of proliferation in cultured human skeletal muscle cells and C2C12 myoblast cells during myogenic differentiation, although the authors applied rottlerin to investigate the effects of the inhibition of PKCdelta in these experiments [37]. In our experiments, administration of either the empty or the PKCdelta shRNA-containing vector into cells of HDC caused a significant decrease in PKC activity assayed on day 3. The approximately $70 \%$ decrease in PKC activity values detected in HDC transfected with the shRNA-containing vector may reflect on the fact that reduction of the efficacy of chondrogenesis itself could have led to an inhibition of PKC activity. Another possibility is that PKCdelta might be involved in the regulation of the activity of other members of the PKC family. This idea is based on the theory of Toker, who proposed that some PKC isoenzymes can activate other PKCs via phosphorylation in a cascade-like manner [38].

Since PKCdelta gene silencing effectively decreased PKC enzymatic activity and led to an almost complete inhibition of in vitro cartilage matrix production, the expression of the molecular regulators of chondrogenesis was also investigated. While the mRNA expression of Sox9 was not affected, its protein expression and phosphorylation were markedly reduced as a result of the introduction of PKCdelta shRNA, and this reduction can partially be accounted for the observed effects on metachromatic cartilage matrix production. Inhibition of PKCdelta activity in osteoblasts by using siRNA has led to a decrease in the phosphorylation and activity of ERK1/2, which in turn has suppressed the differentiation of diosmetin-induced differentiation of these cells [39]. On the contrary, activation of PKCdelta was found to decrease the activity of ERK1/2 in keratinocytes [40]. Moreover, PKCdelta altered differently the phosphorylation of ERK1/2 in human primary skeletal muscle cells and C2C12 rat myogenic cells [37]. Although neither the mRNA nor the protein expression of ERK1/2 showed any alterations as a result of PKCdelta gene silencing in our experimental system, the level of its phosphorylated form exhibited a two-fold increase. If the observation that younger chondroblasts have the highest ERK activity in HDC is taken into consideration, it seems to be plausible to conclude that the persistently elevated ERK1/2 activity may block further differentiation of chondroblasts and in this way could be a factor involved in the complete inhibition of in vitro cartilage matrix production following PKCdelta gene silencing. However, application of gene silencing of PKCdelta had variable effects on MEK-ERK1/2 signalling pathway in different systems [39,41,42], but the majority of the investigations describes PKCdelta as a negative regulator of MEK-ERK1/2 pathway [43]. As we failed to detect any elevation in the phosphorylation of ERK1/2, instead, we found a decreasing pattern following the application of rottlerin, therefore we suppose that this compound is probably not a PKCdelta inhibitor in HDC. This idea is further supported by the fact that we were unable to detect any consistent change of PKCdelta enzyme activity in our experiments when rottlerin was applied to the culture medium of cells for $4-4 \mathrm{~h}$ on days 2 and 3 . However, when rottlerin was added to the reaction mixtures of total PKC enzyme activity assays performed in cell free samples prepared from untreated HDC, it resulted in significantly lower enzyme activities. Nonetheless, the contradiction can be resolved if we hypothesise that rottlerin might have different effects when applied to cells or to an in vitro enzyme activity assay. As we have already mentioned, rottlerin has been described as a mitochondrial uncoupler in different cells [11], and a wide range of its effects (including indirect inhibition of PKCdelta) can be regarded as a consequence of this phenomenon.

Taken together, our results suggest that PKCdelta is a positive regulator of in vitro chondrogenesis upstream to the protein expression and phosphorylation of Sox9. Since the activity of ERK1/2 was increased by PKCdelta gene silencing, PKCdelta could also be a negative regulator of the ERK1/2 kinase pathway in HDC. However, our results concerning the involvement of PKCdelta in the MAPK pathway seem to be controversial, as inhibition of PKCdelta activity by rottlerin and PKCdelta gene silencing has led to opposing results. Nevertheless, the apparent confusion can be resolved if the PKCdelta-independent effects of rottlerin are also taken into consideration: rottlerin is reported to inhibit other PKC isoforms as well as other kinases, such as p38-regulated kinase, MAPK-activated protein kinase 2, PKA or CaM-KIII and it can also modulate mitochondrial metabolic processes [11,14]. Because of its diverse and probably non-PKCdelta-specific effects, we do not recommend 
application of rottlerin as an approach for investigating the role of PKCdelta in chondrifying high density micromass cultures.

\section{Conclusions}

The main findings of this work can be summarised as follows. The continuously detectable PKCdelta expression and activity exhibited a peak on days 2 and 3 , when chondrogenic cells differentiate into chondroblasts in HDC. Rottlerin decreased PKC activity in a cell-free assay system, but failed to inhibit PKC activity when it was applied to HDC during culturing. Gene silencing resulted in a significantly lower PKC activity. Both rottlerin and PKCdelta shRNA caused a severe reduction in cartilage formation as well as in the protein and phospho-protein levels of Sox9. Rottlerin reduced, while PKCdelta gene silencing elevated the phosphorylation status of ERK1/2. On the basis of our results, we concluded that PKCdelta stimulates in vitro chondrogenesis via influencing Sox9 and ERK1/2 phosphorylation, but inhibition of cartilage formation in the rottlerin-treated HDC is presumably a PKCdelta-independent process.

\section{Acknowledgements}

The authors thank Mrs. Krisztina Bíró and Mrs. Júlia Bárány at the Department of Anatomy for their skilful and excellent technical assistance. This work was supported by grants from the Hungarian Science Research Fund (OTKA CNK 80709) and the Hungarian Ministry of Health (ETT 022/09).

\section{Appendix. Supplementary material}

Supplementary material associated with this paper can be found, in the online version, at doi:10.1016/j.biochi.2010.09.005.

\section{References}

[1] H.M. Kronenberg, Developmental regulation of the growth plate, Nature 423 (2003) 332-336

[2] S.H. Chang, C.D. Oh, M.S. Yang, S.S. Kang, Y.S. Lee, J.K. Sonn, J.S. Chun, Protein kinase $C$ regulates chondrogenesis of mesenchymes via mitogen-activated protein kinase signaling, J. Biol. Chem. 273 (1998) 19213-19219.

[3] B. Choi, J.S. Chun, Y.S. Lee, J.K. Sonn, S.S. Kang, Expression of protein kinase C isozymes that are required for chondrogenesis of chick limb bud mesenchymal cells, Biochem. Biophys. Res. Commun. 216 (1995) 1034-1040.

[4] G.X. Shen, Selective protein kinase C inhibitors and their applications, Curr. Drug Targets Cardiovasc. Haematol. Disord. 3 (2003) 301-307.

[5] S.F. Steinberg, Distinctive activation mechanisms and functions for protein kinase Cdelta, Biochem. J. 384 (2004) 449-459.

[6] G. Gorelik, J.Y. Fang, A. Wu, A.H. Sawalha, B. Richardson, Impaired T cell protein kinase Cdelta activation decreases ERK pathway signaling in idiopathic and hydralazine-induced lupus, J. Immunol. 179 (2007) 5553-5563.

[7] D.N. Jackson, D.A. Foster, The enigmatic protein kinase Cdelta: complex roles in cell proliferation and survival, FASEB J. 18 (2004) 627-636.

[8] H.J. Mackay, C.J. Twelves, Targeting the protein kinase $C$ family: are we there yet? Nat. Rev. Cancer 7 (2007) 554-562.

[9] S.P. Davies, H. Reddy, M. Caivano, P. Cohen, Specificity and mechanism of action of some commonly used protein kinase inhibitors, Biochem. J. 351 (2000) 95-105.

[10] Y.A. Choi, D.K. Kim, S.S. Kang, J.K. Sonn, E.J. Jin, Integrin signaling and cell spreading alterations by rottlerin treatment of chick limb bud mesenchymal cells, Biochimie 91 (2009) 624-631.

[11] S.P. Soltoff, Rottlerin: an inappropriate and ineffective inhibitor of PKCdelta, Trends Pharmacol. Sci. 28 (2007) 453-458.

[12] M. Gschwendt, Protein kinase Cdelta, Eur. J. Biochem. 259 (1999) 555-564

[13] U. Kikkawa, H. Matsuzaki, T. Yamamoto, Protein kinase Cdelta (PKCdelta): activation mechanisms and functions, J. Biochem. 132 (2002) 831-839.

[14] J.A. Tapia, R.T. Jensen, L.J. Garcia-Marin, Rottlerin inhibits stimulated enzymatic secretion and several intracellular signaling transduction pathways in pancreatic acinar cells by a non-PKC-delta-dependent mechanism, Biochim. Biophys. Acta 1763 (2006) 25-38.

[15] K. Masur, K. Lang, B. Niggemann, K.S. Zanker, F. Entschladen, High PKC alpha and low E-cadherin expression contribute to high migratory activity of colon carcinoma cells, Mol. Biol. Cell 12 (2001) 1973-1982.
[16] Y. Zhou, D. Wang, F. Li, J. Shi, J. Song, Different roles of protein kinase C-betaI and -delta in the regulation of adipocyte differentiation, Int. J. Biochem. Cell Biol. 38 (2006) 2151-2163.

[17] M. Koyanagi, M. Iwasaki, J. Haendeler, M. Leitges, A.M. Zeiher, S. Dimmeler Wnt5a increases cardiac gene expressions of cultured human circulating progenitor cells via a PKCdelta activation, PLoS. One 4 (2009) e5765.

[18] Q.J. Wang, P. Acs, J. Goodnight, T. Giese, P.M. Blumberg, H. Mischak, J.F. Mushinski, The catalytic domain of protein kinase Cdelta in reciprocal delta and epsilon chimeras mediates phorbol ester-induced macrophage differentiation of mouse promyelocytes, J. Biol. Chem. 272 (1997) 76-82.

[19] P.B. Ahrens, M. Solursh, R.S. Reiter, Stage-related capacity for limb chondrogenesis in cell culture, Dev. Biol. 60 (1977) 69-82.

[20] V. Lefebvre, W. Huang, V.R. Harley, P.N. Goodfellow, C.B. de Crombrugghe, Sox9 is a potent activator of the chondrocyte-specific enhancer of the pro alpha1(II) collagen gene, Mol. Cell Biol. 17 (1997) 2336-2346.

[21] W. Dessau, M.H. von der Mark, M.K. von der Mark, S. Fischer, Changes in the patterns of collagens and fibronectin during limb-bud chondrogenesis, J. Embryol. Exp. Morphol. 57 (1980) 51-60.

[22] W.M. Kulyk, J.L. Franklin, L.M. Hoffman, Sox9 expression during chondrogenesis in micromass cultures of embryonic limb mesenchyme, Exp. Cell Res. 255 (2000) 327-332.

[23] C. Matta, J. Fodor, Z. Szijgyarto, T. Juhasz, P. Gergely, L. Csernoch, R. Zakany, Cytosolic free $\mathrm{Ca} 2+$ concentration exhibits a characteristic temporal pattern during in vitro cartilage differentiation: a possible regulatory role of calcineurin in Ca-signalling of chondrogenic cells, Cell Calcium 44 (2008) $310-323$.

[24] G. Valacchi, A. Pecorelli, M. Mencarelli, P. Carbotti, V. Fortino, M. Muscettola, E. Maioli, Rottlerin: a multifaced regulator of keratinocyte cell cycle, Exp. Dermatol. 18 (2009) 516-521.

[25] J.K. Sonn, M. Solursh, Activity of protein kinase C during the differentiation of chick limb bud mesenchymal cells, Differentiation 53 (1993) 155-162.

[26] Y.M. Yoon, C.D. Oh, S.S. Kang, J.S. Chun, Protein kinase A regulates chondrogenesis of mesenchymal cells at the post-precartilage condensation stage via protein kinase C-alpha signaling, J. Bone Miner. Res. 15 (2000) 2197-2205.

[27] V. Grill, M.A. Sandrucci, M. Basa, V. Nicolin, P. Narducci, R. Bareggi, A.M. Martelli, Immunochemical and immunocytochemical expression of protein kinase $\mathrm{C}$ isoenzymes alpha, delta, epsilon and zeta in primary adherent cultures of chick chondrocytes, Ital. J. Anat. Embryol. 107 (2002) 73-84.

[28] Y. Fan, Y.Q. Zhang, D.J. Sun, Y.N. Zhang, X.W. Wu, J. Li, Rottlerin protected dopaminergic cell line from cytotoxicity of 6-hydroxydopamine by inhibiting PKCdelta phosphorylation, Neurosci. Bull. 25 (2009) 187-195.

[29] S. Kim, J. Hwang, W.H. Lee, D.Y. Hwang, K. Suk, Role of protein kinase Cdelta in paraquat-induced glial cell death, J. Neurosci. Res. 86 (2008) 2062-2070.

[30] J.R. Klinger, J.D. Murray, B. Casserly, D.F. Alvarez, J.A. King, S.S. An, G. Choudhary, A.N. Owusu-Sarfo, R. Warburton, E.O. Harrington, Rottlerin causes pulmonary edema in vivo: a possible role for PKCdelta, J. Appl. Physiol. 103 (2007) 2084-2094.

[31] T. Kurosu, K. Tsuji, A. Kida, T. Koyama, M. Yamamoto, O. Miura, Rottlerin synergistically enhances imatinib-induced apoptosis of BCR/ABL-expressing cells through its mitochondrial uncoupling effect independent of protein kinase Cdelta, Oncogene 26 (2007) 2975-2987.

[32] B.E. Bobick, W.M. Kulyk, The MEK-ERK signaling pathway is a negative regulator of cartilage-specific gene expression in embryonic limb mesenchyme, J. Biol. Chem. 279 (2004) 4588-4595.

[33] R. Zakany, Z. Szijgyarto, C. Matta, T. Juhasz, C. Csortos, K. Szucs, G. Czifra T. Biro, L. Modis, P. Gergely, Hydrogen peroxide inhibits formation of cartilage in chicken micromass cultures and decreases the activity of calcineurin: implication of ERK1/2 and Sox9 pathways, Exp. Cell Res. 305 (2005) 190-199.

[34] M.R. Seghatoleslami, J.A. Roman-Blas, A.M. Rainville, R. Modaressi, K.G. Danielson, R.S. Tuan, Progression of chondrogenesis in C3H10T1/2 cells is associated with prolonged and tight regulation of ERK1/2, J. Cell Biochem. 88 (2003) 1129-1144

[35] R. Tuli, S. Tuli, S. Nandi, X. Huang, P.A. Manner, W.J. Hozack, K.G. Danielson, D.J. Hall, R.S. Tuan, Transforming growth factor-beta-mediated chondrogenesis of human mesenchymal progenitor cells involves $\mathrm{N}$-cadherin and mitogen-activated protein kinase and Wnt signaling cross-talk, J. Biol. Chem. 278 (2003) 41227-41236.

[36] B.E. Bobick, A.I. Matsche, F.H. Chen, R.S. Tuan, The ERK5 and ERK1/2 signaling pathways play opposing regulatory roles during chondrogenesis of adult human bone marrow-derived multipotent progenitor cells, J. Cell Physiol. 224 (2010) 178-186.

[37] G. Czifra, I.B. Toth, R. Marincsak, I. Juhasz, I. Kovacs, P. Acs, L. Kovacs, P.M. Blumberg, T. Biro, Insulin-like growth factor-I-coupled mitogenic signaling in primary cultured human skeletal muscle cells and in C2C12 myoblasts. A central role of protein kinase Cdelta, Cell Signal. 18 (2006) 1461-1472.

[38] A. Toker, Signaling through protein kinase C, Front. Biosci. 3 (1998) D1134-D1147.

[39] Y.L. Hsu, P.L. Kuo, Diosmetin induces human osteoblastic differentiation through the protein kinase C/p38 and extracellular signal-regulated kinase $1 / 2$ pathway, J. Bone Miner. Res. 23 (2008) 949-960. 
[40] T. Efimova, A.M. Broome, R.L. Eckert, Protein kinase Cdelta regulates keratinocyte death and survival by regulating activity and subcellular localization of a p38delta-extracellular signal-regulated kinase 1/2 complex, Mol. Cell Biol. 24 (2004) 8167-8183.

[41] Y.M. Lee, W.H. Li, Y.K. Kim, K.H. Kim, J.H. Chung, Heat-induced MMP-1 expression is mediated by TRPV1 through PKCalpha signaling in HaCaT cells, Exp. Dermatol. 17 (2008) 864-870.
[42] B. Liu, E.J. Ryer, R. Kundi, K. Kamiya, H. Itoh, P.L. Faries, K. Sakakibara, K.C. Kent, Protein kinase Cdelta regulates migration and proliferation of vascular smooth muscle cells through the extracellular signal-regulated kinase 1/2, J. Vasc. Surg. 45 (2007) 160-168.

[43] G.K. Lonne, K.C. Masoumi, J. Lennartsson, C. Larsson, Protein kinase Cdelta supports survival of MDA-MB-231 breast cancer cells by suppressing the ERK1/2 pathway, J. Biol. Chem. 284 (2009) 33456-33465.

Please cite this article in press as: C. Matta, et al., PKCdelta is a positive regulator of chondrogenesis in chicken high density micromass cell cultures, Biochimie (2010), doi:10.1016/j.biochi.2010.09.005 